\title{
EDITORIAL NOTE \\ Critical review of radiopharmaceutical-drug interactions, unexpected new age for a Tupiguarani settlement, and the $h$-index in the Brazilian Academy of Sciences
}

This volume of the Anais da Academia Brasileira de Ciências (AABC) provides several especially interesting papers. For this editorial note we would like to emphasize some articles that will surely foster discussions for years to come.

One article discusses the use of radiopharmaceuticals that nowadays plays a critical role in monitoring and diagnosing several diseases. But can the results be trusted and what are the risks for the patient? Ralph Santos-Oliveira from the Comissão Nacional de Energia Nuclear (CNEN) and colleagues review the problems involved in the interactions between drugs and radiopharmaceuticals. They point out the need for a comprehensive report on the negative consequences of alteration produced by drugs when radiopharmaceuticals are employed in treating human diseases.

Where did the Tupiguarani populations originate and when did they arrive at the coastal region of Southeastern Brazil? Led by Rita Scheel-Ybert, from the Museu Nacional of the Universidade Federal do Rio de Janeiro (MN/UFRJ), new ages for Tupiguarani settlement in the Rio de Janeiro State, more specifically from charcoal samples of anthropogenic origin collected at the Morro Grande site in Araruama, were obtained. Surprisingly, these dates are much older than any reported so far, casting doubts about previous theories regarding the origin and dispersion of Tupiguarani populations. Perhaps the history of how those populations have occupied Brazil might have to be rewritten as more archeological evidence comes to light.

A quite sensitive subject is addressed by Alexander W.A. Kellner (MN/UFRJ) and Luiza C.M.O. Ponciano (Instituto de Geociências, Universidade Federal do Rio de Janeiro): the $h$-index in the Brazilian Academy of Sciences (BAS). The limitation in funding and jobs for science in general has led to the introduction of bibliometric parameters that supposedly help in evaluation procedures. The most popular is the $h$-index that is being slowly introduced in developing countries such as Brazil. An evaluation of this index in BAS however, was quite disappointing and demonstrates that caution is needed if this parameter becomes paramount in scientific rulings. Other problems of bibliometric indices that stem from the increasing pressure to produce a constant flow of new publications ("the bakery effect") are also addressed in this study. Admittedly controversial, this contribution will generate discussions at different levels. However, as one reviewer commented, this is a paper that needed to be written.

Alexander W.A. Kellner

Editor-in-chief 